\title{
Transcript levels of ten caste-related genes in adult diploid males of Melipona quadrifasciata (Hymenoptera, Apidae) - A comparison with haploid males, queens and workers
}

\author{
Andreia A. Borges ${ }^{1}$, Fernanda C. Humann ${ }^{2}$, Lucio A. Oliveira Campos ${ }^{1}$, Mara G. Tavares ${ }^{1}$ \\ and Klaus Hartfelder ${ }^{2}$ \\ ${ }^{1}$ Departamento de Biologia Geral, Universidade Federal de Viçosa, Viçosa, MG, Brazil. \\ ${ }^{2}$ Departamento de Biologia Celular e Molecular e Bioagentes Patogênicos, \\ Faculdade de Medicina de Ribeirão Preto, Universidade de São Paulo, Ribeirão Preto, SP, Brazil.
}

\begin{abstract}
In Hymenoptera, homozygosity at the sex locus results in the production of diploid males. In social species, these pose a double burden by having low fitness and drawing resources normally spent for increasing the work force of a colony. Yet, diploid males are of academic interest as they can elucidate effects of ploidy (normal males are haploid, whereas the female castes, the queens and workers, are diploid) on morphology and life history. Herein we investigated expression levels of ten caste-related genes in the stingless bee Melipona quadrifasciata, comparing newly emerged and 5-day-old diploid males with haploid males, queens and workers. In diploid males, transcript levels for dunce and paramyosin were increased during the first five days of adult life, while those for diacylglycerol kinase and the transcriptional co-repressor groucho diminished. Two general trends were apparent, (i) gene expression patterns in diploid males were overall more similar to haploid ones and workers than to queens, and (ii) in queens and workers, more genes were up-regulated after emergence until day five, whereas in diploid and especially so in haploid males more genes were down-regulated. This difference between the sexes may be related to longevity, which is much longer in females than in males.
\end{abstract}

Key words: stingless bee, real time PCR, caste, diploid male, differential gene expression.

Received: March 8, 2011; Accepted: September 15, 2011.

\section{Introduction}

Sex and caste determination in stingless bees are contentiously debated issues, ever since a genetic predetermination to the female caste phenotypes, the queens and workers, has been proposed for the genus Melipona (Kerr, 1948, 1950), contrasting with the more common mode of caste determination in social Hymenoptera which is based on differential nutrition of the larvae (for review see Hartfelder and Engels, 1998; Hartfelder et al., 2006).

Leaving aside its initial triggers, differentiation of the caste phenotypes in social Hymenoptera is an integral part of postembryonic development. Best analyzed in the honey bee, Apis mellifera, queen/worker differentiation is driven by epigenetic factors (Kucharski et al., 2008) and the endocrine system, especially so juvenile hormone and ecdysteroid titers (Rachinsky et al., 1990), as well as insulin

Send correspondence to Klaus Hartfelder. Departamento de Biologia Celular e Molecular e Bioagentes Patogênicos, Faculdade de Medicina de Ribeirão Preto, Universidade de São Paulo, Avenida Bandeirantes 3900, 14049-900 Ribeirão Preto, SP, Brazil. E-mail: klaus@fmrp.usp.br. signaling (Wheeler et al., 2006; Azevedo and Hartfelder, 2008).

While the developmental processes and roles of the queen and worker castes in division of labor within colonies of highly eusocial bees are fairly well understood, only little is known about the third morph present within colonies, the males. As in all Hymenoptera, and first shown around 1840 by the Polish priest and bee researcher Johan Dzierzon, the males of bees develop from unfertilized eggs, in contrast to females which are diploid and develop from fertilized eggs. The mechanism underlying sex determination in haplo-diploid Hymenoptera was first described by Whiting (1943) in the parasitic wasp Bracon hebetor as a series of multiple alleles at a single sex locus that functionally interact in complementary sex determination (CSD). Heterozygosity at this locus is the genetic basis for female development, whereas hemi- or homozygosity is a determinant for the male sex. While haploidy, and consequent hemizygosity at the sex locus is the primary cause for male development, the occurrence of diploid males has been noted in several hymenopteran species as a result of latent inbreeding and consequent allelic matches at the sex locus 
(van Wilgenburg et al., 2006). The csd locus has been mapped and sequenced in the honey bee (Beye et al., 2003) and was shown to be highly variable within honey bee populations as a result of positive selection (Hasselmann and Beye, 2004). It represents the input to the early embryonic sex determination pathway that has as its output signal male and female Doublesex (Dsx) isoforms produced through alternative splicing (Gempe et al., 2009).

Allelic matching at the $c s d$ locus, occurring either naturally as a consequence of loss of genetic variability within a honey bee population, or experimentally imposed through brother-sister mating, or even more so by instrumental insemination of an unmated queen with sperm from one of her own sons, leads to the development of $50 \%$ of the fertilized eggs as diploid males. Due to this significant loss in the worker force, diploid male production represents a burden to colony growth and productivity (Page Jr and Laidlaw, 1982; Woyke, 1984). This long-term primary cost can only be eliminated through queen replacement. In contrast, a secondary cost factor, which is the consumption of valuable larval food by diploid male larvae can be reduced, and honey bees do so quite efficiently by removing diploid males at a very early larval stage. Nursing workers perceive these through a "cannibalization signal" (Woyke, 1967), which is thought to represent an altered cuticular hydrocarbon profile of the diploid male larvae (Santomauro et al., 2004).

Such early removal of diploid males is not an option for stingless bees, which mass provision brood cells and seal these as soon as an egg has been laid on top of the larval food in a behavioral sequence known as provisioning oviposition process (POP), which is an elementary kernel in stingless bee reproductive biology (Zucchi et al., 1999). While not having the early diploid-male-removal option is a disadvantageous developmental constraint for stingless bees, it provides a window of opportunity for studying the biology of diploid males in highly eusocial bees, as it does not require cumbersome in vitro rearing of larvae, as is necessary in honey bees (Woyke, 1963). Diploid males of Melipona quadrifasciata were first successfully produced by Camargo $(1974,1979)$ through a brother-sister mating protocol, and this has aided research on their life history (Camargo, 1982).

Behavioral, morphological, and cuticular hydrocarbon comparisons between haploid males and females of stingless bees have shown that meliponine males are more similar to workers than to queens (Campos et al., 1979; Almeida, 1985; Bonetti and Kerr, 1985; Kerr et al., 2004). Furthermore, males of stingless bees have occasionally been seen to participate in colony maintenance activities, such as food exchange and nectar dehydration (ImperatrizFonseca, 1973; van Veen et al., 1997).

Hardly anything is known about the behavior of diploid males of stingless bees, primarily so because they cannot easily be distinguished from the normal haploid ones; this only being possible through post mortem karyotyping. But they are reported to have shorter life spans (Camargo, 1982), smaller testes, and less sperm (Tavares et al., 2003). Smaller testes and lower sperm numbers have also been denoted in diploid drones of honey bees (Woyke, 1973; Chaud-Netto and Kerr, 1980), as well as in bumble bees (Duchateau and Mariën, 1995).

The lack of morphological variation among haploid and diploid males on the one hand, and the differences in life span and fertility on the other made us ask as to whether such discrepancies might correlate with differences in gene expression patterns. In the present study we investigated transcript levels of ten genes previously identified as differentially expressed in the female castes of the stingless bee Melipona quadrifasciata (Judice et al., 2004, 2006), comparing their relative expression levels in diploid males to that of haploid ones, as well as to queens and workers. Real time RT-PCR assays were run on two time points in the adult life cycle, viz. on day 0 , shortly after they emerged from the brood combs and when they were five days old. We chose to look at this early window in adult life because it covers the period of adult sexual maturation, including the migration of spermatozoa from the testes to the seminal vesicles (Camargo, 1984). Furthermore, it is the window of major changes in the endocrine system of $M$. quadrifasciata males, this being as a sharp peak in the ecdysteroid hemolyph titer that occurs in conjunction with a broader peak in the juvenile hormone titer (Santana and Hartfelder, unpublished results).

\section{Materials and Methods}

\section{Bees and total RNA extraction}

Males and females of the stingless bee Melipona quadrifasciata were collected from colonies kept at the meliponary of the Federal University of Viçosa, Viçosa, MG, Brazil. Haploid males, workers and queens were retrieved from combs taken from strong colonies which did not show signs of inbreeding, whereas diploid males were obtained from inbred colonies set up through a brothersister mating scheme (Camargo, 1974, 1979). Ploidy of these males was determined by cytogenetic analysis (Imai et al., 1988).

Brood combs containing late pupal stages were removed from the colonies and kept in an incubator at $28^{\circ} \mathrm{C}$. Day- 0 bees were collected within 4-6 $\mathrm{h}$ after emerging from the brood cells. To assess transcript abundance in 5-day-old adults, such newly emerged bees were kept in Petri dishes in an incubator $\left(28^{\circ} \mathrm{C}\right)$ with ad libitum access to sugar syrup $(50 \%)$ and fermented pollen (Camargo, 1979). All individuals were snap frozen in liquid nitrogen and stored at $-80^{\circ} \mathrm{C}$.

For RNA extraction, two individuals of each type and age class were pooled and homogenized in $1 \mathrm{~mL}$ of TRIzol reagent (Invitrogen) following the manufacturer's protocol. The resultant RNA pellet was resuspended in diethyl 
pyrocarbonate-treated water. A DNase treatment $(0.1 \mathrm{U}$ RNase-free DNAse I, Invitrogen) was done to eliminate potential genomic DNA contamination.

All RNA samples (five per phenotype and age class) were assayed for purity, RNA integrity and concentration through spectrophotometric determination of $\mathrm{OD}_{260} / \mathrm{OD}_{280}$ ratios, these ranging from 1.8 to 2.0, and electrophoresis in agarose gels run under denaturing conditions. Subsequently, the samples were stored at $-80^{\circ} \mathrm{C}$ for quantitative real time PCR (RT-qPCR) analysis.

\section{Primer design and RT-qPCR analysis}

In the present study, we analyzed the transcript levels of ten genes. The first four encode a transmembrane transporter (TM-transporter), a permease, a ceramide kinase, and a gene of unknown function, provisionally named $M q 5$. They were chosen from a gene set revealed as differentially expressed in a custom-made microarray for $M$. quadrifasciata (Judice, Pereira and Hartfelder, unpublished).

The gene herein named TM-transporter corresponds to a Melipona RDA library EST sequence (GenBank accession number CO729459.1); it has sequence similarity with the Drosophila gene CG1607 which encodes a predicted transmembrane transporter. The gene named permease corresponds to a Melipona RDA library EST sequence (GenBank accession number CO578735.1); it is similar to the Drosophila gene CG2316 which has as Gene Ontology molecular function predictions: ATPase activity, coupled to transmembrane movement of substances, these characterizing it as a permease. The gene named ceramide kinase corresponds to a Melipona RDA library EST sequence (GenBank accession number CO578687.1); it is similar to the Drosophila gene CG16708, Cerk, which has experimentally validated ceramide kinase activity. The gene named $M q 5$ is a Melipona RDA library sequence (GenBank accession number CO578601.1); it is an EST without significant similarity to genes of other organisms. EST clones for these four genes were re-sequenced and gene identification checked by blastx and blastn searches against GenBank sequences and the dbEST database for Melipona quadrifasciata. Subsequently, gene-specific primers were designed by means of the Primer 3 and Gene Runner version 3.05 softwares.

The other six genes included in the study were for ESTs encoding dunce (GenBank accession number CO729450.1), paramyosin (CO729458.1), groucho (CO729465.1), an amino acid-polyamine transporter (AAP-transporter; CO729459.1), a fatty acid synthase (FAS; CO729464.1) and diacylglycerol kinase (DGK; CO729466.1), which had already been validated as differentially expressed in newly emerged $M$. quadrifasciata queens and workers (Judice et al., 2006). All PCR primer sequences are listed in Table 1.

Table 1 - Real-time PCR primer sequences and their respective target genes.

\begin{tabular}{|c|c|c|c|}
\hline Target gene & Primer & Sequence & Source \\
\hline \multirow[t]{2}{*}{ Ribosomal protein 49} & $\mathrm{rp} 49 \mathrm{~F}$ & 5'-CGTCATATGTTGCCAACTGGT-3' & Lourenço et al., 2008 \\
\hline & $\mathrm{rp} 49 \mathrm{R}$ & 5'-TTGAGCACGTTCAACAATGG-3' & \\
\hline \multirow[t]{2}{*}{ Actin } & ActMelF & 5'-CGGGTGGTGCGATAATCTTG-3' & Judice et al., 2004 \\
\hline & actMelR & 5'-GGGTATGGAAGCCTGCGGTATC-3' & \\
\hline \multirow[t]{2}{*}{ Transmembrane transporter } & $\mathrm{Mq1F}$ & 5'-TTGCTATCTCGTGCGTCTTG-3' & This study \\
\hline & $\mathrm{Mq1R}$ & 5'-GCGAACATGCCGAATAAACG-3' & \\
\hline \multirow[t]{2}{*}{ Permease } & $\mathrm{Mq} 2 \mathrm{~F}$ & 5'-CCCGTTAGATGCGACTCAG-3' & This study \\
\hline & $\mathrm{Mq} 2 \mathrm{R}$ & 5'-CATGCTTGTCCGTTTCATATTG-3' & \\
\hline \multirow[t]{2}{*}{ Ceramide kinase } & $\mathrm{Mq} 3 \mathrm{~F}$ & 5'-CACGTTCGTGGTGAAGAAGA-3' & This study \\
\hline & Mq3R & 5'-CCTCGTGTATCCAATCGTCC-3' & \\
\hline \multirow[t]{2}{*}{$M q 5$} & Mq5F & 5'-GGATTTCAAAGTGGCTGGC-3' & This study \\
\hline & Mq5R & 5'-GTTAATCACGTTCAATCGCCC-3' & \\
\hline \multirow[t]{2}{*}{ Dunce } & DunF & 5' -AGCCGACCTGCGACTTCTC-3' & Judice et al., 2006 \\
\hline & DunR & 5' -ACATGGACATTAGCCCAATGTG-3' & \\
\hline \multirow[t]{2}{*}{ Amino acid-polyamine transporter } & AmitranspF & 5' -AGGGAAGATCCCGTCAAGAA-3' & Judice et al., 2006 \\
\hline & AmitranspR & 5' -GGGTCGTGTAAAATGCCATGT-3' & \\
\hline \multirow[t]{2}{*}{ Paramyosin } & PmyosF & 5' -ATCCGAGGGAAGATCCAGGTA-3' & Judice et al., 2006 \\
\hline & PmyosR & 5' -TGCCTCTTGTAGATGCTCATTTTC-3' & \\
\hline \multirow[t]{2}{*}{ Diacylglycerol kinase } & DGKF & 5' -CTTCGTATCGATGCCAGCAA-3' & Judice et al., 2006 \\
\hline & DGKR & 5' -TTTTGTTGTTCGTCAATCCGTTT-3' & \\
\hline \multirow[t]{2}{*}{ Fatty acid synthase } & FASF & 5' -GATCGCGGGATTGATACCTACT-3' & Judice et al., 2006 \\
\hline & FASR & 5' -TCGACGGTAACAAAAGTCAAGGA-3' & \\
\hline \multirow[t]{2}{*}{ Groucho } & GrouF & 5' -CGGCGGACGGTTCGA-3' & Judice et al., 2006 \\
\hline & GrouR & 5' -GATCCCACGAACGCACTGT-3' & \\
\hline
\end{tabular}


First strand cDNA templates were synthesized from $5 \mu \mathrm{g}$ of DNase-treated RNA using Superscript II (Invitrogen) reverse transcriptase and oligo $(\mathrm{dT})_{12-18}$ primer (Invitrogen). Subsequently, optimal cDNA quantities were established for the target, as well as the reference genes ( $r i$ bosomal protein 49 and actin). Serial dilution series made from PCR products of the ten genes were used to calculate primer efficiencies, defined as efficiency $=10\left({ }^{-1 / \text { slope }}\right)$ (Pfaffl, 2001).

Each reaction mixture consisted of $7 \mu \mathrm{L}$ of SYBR Green (Applied Biosystems), $1 \mu \mathrm{L}$ of cDNA (diluted 1:10) and $0.8 \mu \mathrm{L}$ of each gene-specific forward and reverse primer $(10 \mathrm{pmol} / \mu \mathrm{L})$ in a final volume of $14 \mu \mathrm{L}$. PCR amplifications were done in an ABI Prism 7500 system (Applied Biosystems) with the following thermal cycling profile: $50^{\circ} \mathrm{C}$ for $2 \mathrm{~min}, 95^{\circ} \mathrm{C}$ for $10 \mathrm{~min}$, followed by 40 steps of $95^{\circ} \mathrm{C}$ for $15 \mathrm{~s}$ and $60^{\circ} \mathrm{C}$ for $1 \mathrm{~min}$. After 40 amplification cycles, all samples were submitted to dissociation curve analysis to confirm the absence of nonspecific products and primer dimers. In each run, a non-template reaction was included as negative control. None of the negative control samples showed a fluorescence signal, confirming that the extraction procedure and DNase treatment were efficient in removing residual genomic DNA. Two inter-run calibrators were included in each plate to correct for run-to-run variation, as suggested in the MIQE recommendations (Bustin et al., 2009). We analyzed a total of 40 RNA samples, 20 for each age class, and these being divided into five from each phenotype (diploid and haploid males, queens and workers). All samples were analyzed in triplicate to assure repeatability.

Fold variation in transcript levels was calculated using the comparative Ct method (Pfaffl, 2001). Data were analyzed using the REST program (Pfaffl et al., 2002), which uses a pairwise fixed reallocation randomization testing procedure on expression ratios among treatments. $\mathrm{P}$ values $\leq 0.05$ were considered as statistically significant.

\section{Results}

In a first step, we investigated changes in transcript levels that occurred during the first five days of adult life in diploid males (Figure 1A), haploid males (Figure 1B), workers (Figure 1C) and queens (Figure 1D). The box and whisker plots give the expression ratio (fold change) for each gene at day 5 in relation to day 0 .

In diploid males, two genes, dunce and paramyosin were significantly up-regulated (REST, $\mathrm{p} \leq 0.05$ ), whereas diacylglycerol kinase $(D G K)$ and groucho expression was down-regulated. In haploid males, two genes, fatty acid synthase $(F A S)$ and again groucho were significantly less expressed. In workers, the transcript levels of transmembrane transporter (TM-transporter), ceramide kinase and also dunce were significantly higher in 5 dayold individuals when compared to newly emerged ones. In queens, up-regulation was denoted for TM-transporter, ceramide kinase, and down-regulation for paramyosin.

In a second step we compared the transcript level of each of the ten genes across phenotypes. In these comparisons, we set the focus on diploid males and calculated gene expression differences as fold change through pairwise REST comparisons of the levels in diploid males (set as 1) against haploid males, workers and queens. In newly emerged haploid males (Table 2), transcript levels were higher for paramyosin and FAS and lower for ceramide kinase and $D G K$ when compared to diploid males. Newly emerged workers had lower expression levels for three genes (TM-transporter, ceramide kinase and groucho) than diploid males, whereas in queens, seven of the ten genes turned out to be over-expressed.

In 5-day-old diploid males (Table 3), expression levels continued to be lower for ceramide kinase and $D G K$, and were now also lower for groucho when compared to haploid males. Workers had lower expression levels for two genes (dunce and paramyosin) than diploid males. In contrast, transcript levels in 5-day-old queens continued to be higher for six out of ten genes, except for paramyosin, which was now less expressed than in diploid males of the same age.

The overall picture on gene expression levels for the ten caste-related genes in M. quadrifasciata males and females can thus be summarized as follows. Irrespective of ploidy levels in the male sex, two genes, dunce and groucho, showed similar trends in their regulation with regard to age, with dunce being up and groucho downregulated in 5-day-old males. For females, similarities between the castes were denoted in the directionality of agerelated change in TM-transporter, ceramide kinase and paramyosin expression, the first two being up and the latter down-regulated in 5-day-old queens and workers. A second

Table 2 - Pairwise comparisons for gene expression levels in newly emerged diploid males against haploid males, workers and queens. Foldchange and direction are given based on REST (Pfaffl et al., 2002) results. Only statistically significant differences $(\mathrm{p} \leq 0.05)$ are shown.

\begin{tabular}{lccc}
\hline Gene & Haploid male & Worker & Queen \\
\hline $\begin{array}{l}\text { Transmembrane } \\
\text { transporter }\end{array}$ & & $3.01 \times$ down & $1.64 \times$ up \\
Permease & & $2.42 \times$ up \\
Ceramide kinase & 2.08.x down & $2.86 \times$ down & \\
Mq5 & & $2.31 \times$ up \\
Dunce & & $2.90 \times$ up \\
Amino acid-polyamine & & $2 ., 67 \times$ up \\
transporter & & \\
Paramyosin & $2.19 \times$ up & & \\
Diacylglycerol kinase & $2.05 \times$ down & & \\
Fatty acid synthase & $2.01 \times$ up & & $2.38 \times$ up \\
Groucho & & $4.34 \times$ down & \\
\hline
\end{tabular}




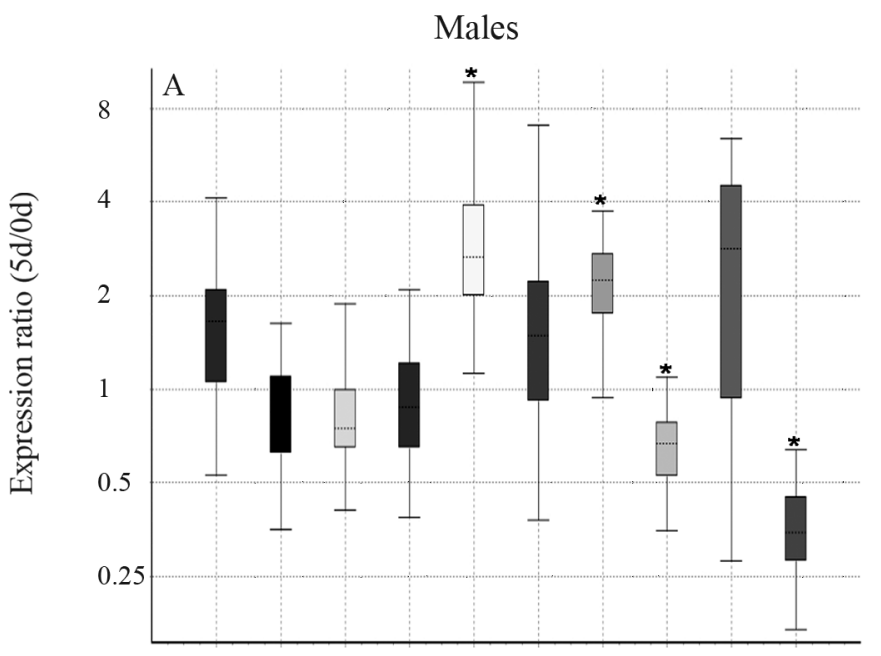

Females
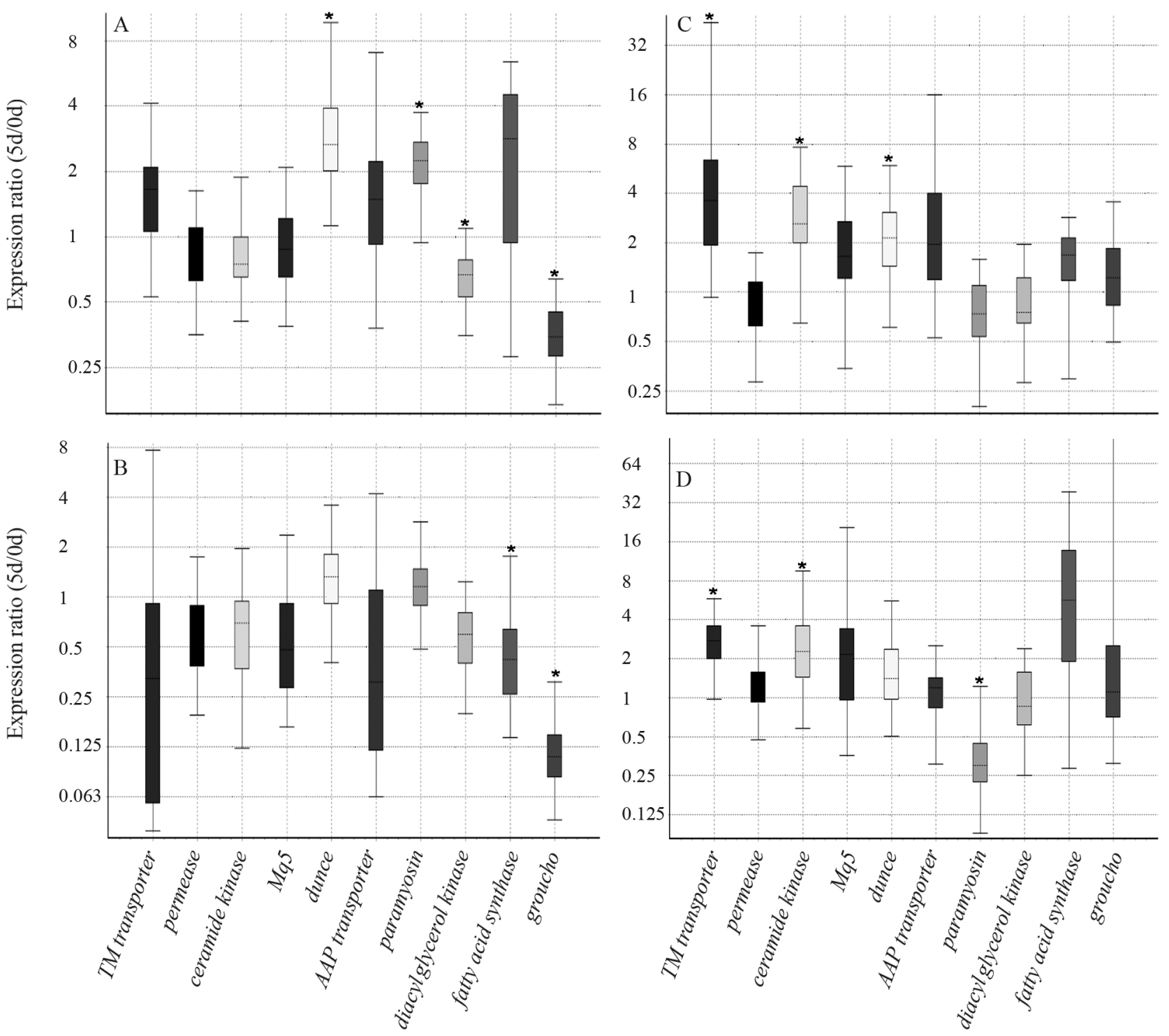

Figure 1 - Changes in gene expression levels during early adult life of Melipona quadrifasciata diploid males (A), haploid males (B), workers (C) and queens (D). Fold change values refer to transcript levels detected in five-day old bees in comparison to newly emerged ones (the latter set as equal to 1). Box-and-whisker plots show median (dotted line), upper and lower quartiles (boxed), upper maximum and lower minimum for each gene. Asterisks indicate significant differences (REST randomization significance test, $\mathrm{p} \leq 0.05$ ).

major conclusion was that diploid males are much more similar to haploid males and workers in the expression levels of these genes than they are to queens, both at emergence from the brood cells, as well as during the period of sexual maturation, here studied at day five of adult life.

Before entering the discussion, a caveat needs to be brought up at this point. We noted that the directionality of caste-specific differences in expression levels differed for some of the genes when compared to the results previously reported by Judice et al. (2006). For instance, we found the expression levels for dunce and groucho to be higher in newly emerged queens than in workers of the same age. We attribute these discrepancies, which obviously have conse- quences for the interpretation of RT-qPCR results in relation to caste and division of labor in this social bee, to the use of different reference genes. Whereas Judice et al. (2006) relied on 28S rRNA as reference we followed a more stringent recommendation (Bustin et al., 2009) and used two reference genes, one encoding a cytoplasmatic actin and the other ribosomal protein 49. Furthermore, these two genes had, in the meantime, been validated as suitable reference genes for RT-qPCR studies in the honey bee (Lourenço et al., 2008). We are thus confident that the comparisons on gene expression levels in relation to age and genotype/phenotype presented herein reflect real differences. Furthermore, by using REST software (Pfaffl $e t$ 
Table 3 - Pairwise comparisons for gene expression levels in 5-day-old diploid males against haploid males, workers and queens. Fold-change and direction are given based on REST (Pfaffl et al., 2002) results. Only statistically significant differences $(\mathrm{p} \leq 0.05)$ are shown.

\begin{tabular}{|c|c|c|c|}
\hline Gene & Haploid male & Worker & Queen \\
\hline $\begin{array}{l}\text { transmembrane } \\
\text { transporter }\end{array}$ & & & 2. $85 \times$ up \\
\hline Permease & & & $3.59 \times$ up \\
\hline Ceramide kinase & $2.84 \times$ down & & $1.91 \times$ up \\
\hline$M q 5$ & & & $5.65 \times$ up \\
\hline Dunce & & $1.95 \times$ down & \\
\hline $\begin{array}{l}\text { Amino acid-polyamine } \\
\text { transporter }\end{array}$ & & & \\
\hline Paramyosin & & $1.82 \times$ down & $3.17 \times$ down \\
\hline Diacylglycerol kinase & $2.37 \times$ down & & \\
\hline Fatty acid synthase & & & $5.13 \times$ up \\
\hline Groucho & $1.99 \times$ down & & $4.61 \times$ up \\
\hline
\end{tabular}

al., 2002) we employed a stringent statistical analysis procedure specifically developed for quantitative gene expression analysis.

\section{Discussion}

Among the ten genes for which we quantified expression levels, paramyosin, ceramide kinase, DGK, dunce and groucho showed significant variation with respect to age and among sex and caste phenotypes. Paramyosin is a structural component of insect flight muscle (Beinbrech et al., 1985; Hooper et al., 2008). We would, thus, expect its expression to be related to maturation processes in Melipona flight muscle. The observation that transcription was slightly up-regulated in haploid males (Figure 1), is in accordance with flight muscle maturation in preparation for mating flights of these males (van Veen et al., 1997), but it was rather surprising to see this trend as well in diploid ones, as the latter generally do not leave the colonies. In contrast, the down-regulation in paramyosin expression seen in 5-day-old queens may reflect their earlier adult maturation. Such precociousness can be inferred from the high locomotor activity of young virgin queens which, soon after emergence, must find a safe place within the colony where they can hide to avoid being attacked by workers (Engels and Imperatriz-Fonseca, 1990).

Ceramide kinase mediates the maintenance of ceramide levels, the latter being of importance for the local regulation of phospolipase C (PLC) activity and consequent modulation of intracellular signal transduction by phosphatidylinositol-biphosphate (PIP2). In this context ceramide kinase has been shown to be involved in phototransduction in Drosophila melanogaster (Dasgupta et al., 2009). Interestingly, ceramide kinase expression was significantly upregulated in both female castes of $M$. quadrifasciata within the first days after emergence from the brood cells, but not so in haploid or diploid males (Figure 1). Furthermore, ploidy levels may play a role in ceramide kinase transcription, as it is less expressed in haploid males when compared to diploid ones. Ploidy levels may also be associated with diacylglycerol kinase ( $D G K$ ) expression rates, as indicated through comparisons of haploid with diploid males (Tables 2 and 3). In Drosophila melanogaster, DGK is produced in specific neurons and is part of a neuronal signal transduction pathway (Harden et al., 1993). In honey bees, $D G K$ was denoted as more expressed in brains of old foragers than in newly emerged workers (Tsuchimoto et al., 2004).

Behavioral modulation is also the primary biological function attributed to the gene dunce. It encodes a cyclic AMP phosphodiesterase that is critical for fruit fly neuronal development and learning and memory (Bellen et al., 1987; van Swinderen, 2007). Furthermore, mutations in dunce affect male sexual behavior, and dunce females were unresponsive to sex peptide (Chapman et al., 1996). As we could show, dunce expression is up-regulated in males and females of $M$. quadrifasciata during early adult life, inferring general maturation processes in behavioral responses. In a previous study, its higher expression in newly emerged workers than in queens (Judice et al., 2006) had led us to conclude that it may play a role in cooperative behavior of workers, based on evidence from fruit flies (Tinette et al., 2004). Nevertheless, with the observation in mind that dunce transcript levels were lower in 5-day-old workers than in diploid males (Table 3 ), a role in cooperative behavior seems less likely, because males of stingless bees were only exceptionally seen to participate in colony maintenance activities (Imperatriz-Fonseca, 1973; van Veen et al., 1997).

Compared to the relatively specific roles of the aforementioned genes, groucho is about as multifaceted as its naming patron, Groucho Marx. It encodes a member of the conserved TLE/GRG family of co-repressors for multiple transcription factors (Jennings and Ish-Horowicz, 2008). In the fruit fly, groucho protein is required in neurogenesis, segmentation and sex determination (Paroush et al., 1994). The molecular mechanisms through which groucho acts to repress transcription are now gradually emerging, one of these being its interaction with a histone deacetylase (Winkler et al., 2010), resulting in chromatin modification. As we could show, groucho expression is significantly downregulated in $M$. quadrifasciata males during the first five days of adult life (Figure 1), and there is a divergent picture in relation to females, with groucho transcript levels being significantly lower in newly emerged workers in comparison to diploid males (Table 2), but higher in 5-day-old queens. As it is not a structural gene but a transcriptional modulator, altering groucho levels by means of an RNAi protocol should be a feasible strategy to get a glimpse at its role in social bees, especially since epigenetic modification has been shown to be a major factor in honey bee caste development (Kucharski et al., 2008). 
From a general perspective, a trend that apparently distinguishes the two sexes in M. quadrifasciata is an apparent overall increase in transcript levels in young females, considering that in both queens and workers the median fold changes in expression levels were higher than 1 for seven out of the ten genes at day five (Figure 1). In contrast eight of the ten genes were less expressed in 5-day-old haploid males, and five out of ten were so in diploid males. Possibly, this difference between the sexes may be related to life span, which is much longer in females than in males, not only in M. quadrifasciata (Camargo, 1982) but also in honey bees (Ruttner, 1966) and most other social Hymenoptera. Finally, the largest overall difference in gene expression levels was denoted when comparing diploid males to queens (Tables 2 and 3). Since the gene set used herein was derived from subtractive hybridization libraries contrasting queens and workers, which greatly differ in fertility, life span and roles in the colony, it is plausible that the large discrepancy in gene expression levels seen between diploid males and queens is an even further extrapolation of this trend.

Diploid males are "misfits" in terms of hymenopteran population genetics (van Wilgenburg et al., 2006), and even more so in social species, where they are also a burden on colony productivity and reproductive success (Duchateau and Mariën, 1995; Whitehorn et al., 2009). They are nevertheless of interest for investigating gene regulatory networks underlying phenotype differentiation. Gene regulatory network differences have been computationally predicted from gene expression data in honey bee queen and worker larvae (Cristino et al., 2006; Barchuk et al., 2007), but so far no such predictions exist for comparisons between the sexes. A complicating factor herein are the differences in ploidy levels between normal male and female Hymenoptera, and even though gene dosage may be compensated by alternatively silenced paternal or maternal alleles in the female sex, this may not necessarily be the case for all genes. As we could show herein, candidate genes taken from a suppression subtractive library for $M$. quadrifasciata queens and workers (Judice et al., 2006) varied in their transcript levels in haploid and diploid males, which differ in ploidy but not in morphology, as well as in the female castes which differ in morphology but not in ploidy. Further investigating such gene sets may thus provide fundaments towards building gene networks underlying life history divergence in the castes and sexes of highly social insect.

\section{Acknowledgments}

We thank Carla Judice for access to unpublished microarray data and providing clones from the Melipona quadrifasciata RDA library for re-sequencing and inclusion in this study. This work was supported by FAPEMIG (grant number APQ 01738-09) and a CNPq doctoral scholarship to A.A.B.

\section{References}

Almeida M (1985) Sex determination in bees XXII. Generalized Malahanobis distances between males and females of the stingless bee Melipona scutellaris Latreille 1811. Rev Bras Genet 8:603-608.

Azevedo SV and Hartfelder K (2008) The insulin signaling pathway in honey bee (Apis mellifera) caste development - Differential expression of insulin-like peptides and insulin receptors in queen and worker larvae. J Insect Physiol 54:1064-1071.

Barchuk AR, Cristino AS, Kucharski R, Costa LF, Simoes ZLP and Maleszka R (2007) Molecular determinants of caste differentiation in the highly eusocial honeybee Apis mellifera. BMC Dev Biol 7:e70.

Beinbrech G, Meller U and Sasse W (1985) Paramyosin content and thick filament structure in insect muscles. Cell Tissue Res 241:607-614.

Bellen HJ, Gregory BK, Olsson CL and Kiger Jr JA (1987) Two Drosophila learning mutants, dunce and rutabaga, provide evidence of a maternal role for cAMP on embryogenesis. Dev Biol 121:432-444.

Beye M, Hasselmann M, Fondrk MK, Page Jr RE and Omholt SW (2003) The gene $c s d$ is the primary signal for sexual development in the honeybee and encodes an SR-type protein. Cell 114:419-429.

Bonetti AM and Kerr WE (1985) Estudo da ação gênica em Melipona marginata e Melipona compressipes a partir de análise morfológica. Rev Bras Genet 8:629-638.

Bustin SA, Benes V, Garson JA, Hellemans J, Huggett J, Kubista M, Mueller R, Nolan T, Pfaffl MW, Shipley GL et al. (2009) The MIQE guidelines: Minimum information for publication of quantitative real-time PCR experiments. Clin Chem 55:611-622.

Camargo CA (1974) Produção de machos diplóides de Melipona quadrifasciata (Hymenoptera, Apidae). Ciênc Cult 26:267.

Camargo CA (1979) Sex determination in bees. XI. Production of diploid males and sex determination in Melipona quadrifasciata. J Apic Res 18:77-83.

Camargo CA (1982) Longevity of diploid males, haploid males, and workers of the social bee Melipona quadrifasciata, Hymenoptera, Apidae. J Kansas Entomol Soc 55:8-12.

Camargo CA (1984) Spermatozoa numbers and migration to the seminal vesicles in haploid and diploid males of Melipona quadrifasciata Lep. J Apic Res 23:15-17.

Campos LAO, Kerr WE and Silva DLN (1979) Sex determination in bees. VIII. Relative action of genes $x a$ and $x b$ on sex determination in Melipona bees. Rev Bras Genet 3:267-280.

Chapman T, Choffat Y, Lucas WE, Kubli E and Partridge L (1996) Lack of response to sex-peptide results in increased cost of mating in dunce Drosophila melanogaster females. J Insect Physiol 42:1007-1015.

Chaud-Netto J and Kerr WE (1980) Genetic mechanisms for the development of reproductive organs of Apis mellifera workers and diploid drones: A complementary hypothesis. Braz J Genet 3:127-138.

Cristino AS, Nunes FMF, Lobo CH, Bitondi MMG, Simoes ZLP, Costa LD, Lattorff HMG, Moritz RFA, Evans JD and Hartfelder K (2006) Caste development and reproduction: A genome-wide analysis of hallmarks of insect eusociality. Insect Mol Biol 15:703-714. 
Dasgupta U, Bamba T, Chiantia S, Karim P, Tayoun AN, Yonamine I, Rawat SS, Rao RP, Nagashima K, Fukusaki E et al. (2009) Ceramide kinase regulates phospholipase C and phosphatidylinositol 4, 5, bisphosphate in phototransduction. Proc Natl Acad Sci USA 106:20063-20028.

Duchateau MJ and Mariën J (1995) Sexual biology of haploid and diploid males in the bumble bee Bombus terrestris. Insectes Soc 42:255-266.

Engels W and Imperatriz-Fonseca VL (1990) Caste development, reproductive strategies, and control of fertility in honey bees and stingless bees. In: Engels W (ed) Social Insects - An Evolutionary Approach to Castes and Reproduction. Springer Verlag, Berlin, pp 167-230.

Gempe T, Hasselmann M, Schiott M, Hause G, Otte M and Beye M (2009) Sex determination in honeybees: Two separate mechanisms induce and maintain the female pathway. PLoS Biology 7:e10.

Harden N, Yap S, Chiam M and Lim L (1993) A Drosophila gene encoding a protein with similarity to diacylglycerol kinase is expressed in specific neurons. Biochem J 289:439-444.

Hartfelder K and Engels W (1998) Social insect polymorphism: Hormonal regulation of plasticity in development and reproduction in the honeybee. Curr Topics Dev Biol 40:45-77.

Hartfelder K, Makert GR, Judice CC, Pereira GAG, Santana WC, Dallacqua R and Bitondi MMG (2006) Physiological and genetic mechanisms underlying caste development, reproduction and division of labor in stingless bees. Apidologie 37:144-163.

Hasselmann M and Beye M (2004) Signatures of selection among sex-determining alleles of the honey bee. Proc Natl Acad Sci USA 101:4888-4893.

Hooper SL, Hobbs KH and Thuma JB (2008) Invertebrate muscles: Thin and thick filament structure; molecular basis of contraction and its regulation, catch and asynchronous muscle. Progr Neurobiol 86:72-127.

Imai H, Taylor RW, Crosland MWJ and Crozier RH (1988) Modes of spontaneous evolution in ants with reference to the minimum interaction hypothesis. Jpn J Genet 63:159-185.

Imperatriz-Fonseca VL (1973) Miscellaneous observations on the behavior of Schwarziana quadripunctata (Hym., Apidae, Meliponinae). Bol Zool Biol Mar 30:633-640.

Jennings BH and Ish-Horowicz D (2008) The Groucho/TLE/Grg family of transcriptional co-repressors. Genome Biol 9:e205.

Judice C, Hartfelder K and Pereira GAG (2004) Caste-specific gene expression profile in the stingless bee Melipona quadrifasciata - Are there common patterns in highly eusocial bees? Insectes Soc 51:352-358.

Judice C, Carazolle M, Festa F, Sogayar MC, Hartfelder K and Pereira GAG (2006) Gene expression profiles underlying alternative caste phenotypes in a highly eusocial bee. Insect Mol Biol 15:33-44.

Kerr WE (1948) Estudos sobre o gênero Melipona. Anais Esc Sup Agric Luiz de Queiroz 5:181-291.

Kerr WE (1950) Genetic determination of castes in the genus Melipona. Genetics 35:143-152.

Kerr WE, Jungnickel H and Morgan ED (2004) Workers of the stingless bee Melipona scutellaris are more similar to males than to queens in their cuticular compounds. Apidologie 35:611-618.
Kucharski R, Maleszka J, Foret S and Maleszka R (2008) Nutritional control of reproductive status in honeybees via DNA methylation. Science 319:1827-1830.

Lourenço AP, Mackert A, Cristino AS and Simoes ZLP (2008) Validation of reference genes for gene expression studies in the honey bee, Apis mellifera, by quantitative real-time RTPCR. Apidologie 39:372-385.

Page Jr RE and Laidlaw HH (1982) Closed populations honey bee (Apis mellifera) breeding. 1. Population genetics of sex determination. J Apic Res 21:30-37.

Paroush Z, Finley Jr RL, Kidd T, Wainwright S, Ingham PW, Brent R and Ish-Horowicz D (1994) Groucho is required for Drosophila neurogenesis, segmentation, and sex determination and interacts directly with Hairy-related bHLH proteins. Cell 79:805-815.

Pfaffl MW (2001) A new mathematical model for relative quantification in real-time RT-PCR Nucleic Acids Res 29:e45.

Pfaffl MW, Horgan GW and Dempfle L (2002) Relative expression software tool (REST) for group-wise comparison and statistical analysis of relative expression results in real-time PCR. Nucleic Acids Res 30:e36.

Rachinsky A, Strambi C, Strambi A and Hartfelder K (1990) Caste and metamorphosis - hemolymph titers of juvenile hormone and ecdysteroids in last instar honeybee larvae. Gen Comp Endocrinol 79:31-38.

Ruttner F (1966) The life and flight activity of drones. Bee World 47:93-100.

Santomauro G, Oldham NJ, Boland W and Engels W (2004) Cannibalism of diploid drone larvae in the honey bee (Apis mellifera) is released by odd pattern of cuticular substances. J Apic Res 43:69-74.

Tavares MG, Irsigler AST and Campos LAO (2003) Testis length distinguishes haploid from diploid drones in Melipona quadrifasciata (Hymenoptera, Meliponinae). Apidologie 34:449-455.

Tinette S, Zhang L and Robichon A (2004) Cooperation between Drosophila flies in searching behavior. Genes Brains Behav 3:39-50.

Tsuchimoto M, Aoki M, Takada M, Danou Y, Sasagawa H, Kitagawa Y and Kadowaki T (2004) The changes of gene expression in honey bee (Apis mellifera) brains associated with ages. Zool Sci 21:23-28.

van Swinderen B (2007) Attention-like processes in Drosophila require short-term memory genes. Science 315:1590-1593.

van Veen JV, Sommeijer MJ and Meeuwsen F (1997) Behaviour of drones in Melipona (Apidae, Meliponinae). Insectes Soc 44:435-447.

van Wilgenburg E, Driessen G and Beukeboom LW (2006) Single locus complementary sex determination in Hymenoptera: An ‘intelligent' design? Frontiers Zool 3:e1.

Wheeler DE, Buck N and Evans JD (2006) Expression of insulin pathway genes during the period of caste determination in the honey bee, Apis mellifera. Insect Mol Biol 15:597-602.

Whitehorn PR, Tinsley MC, Brown MJF, Darvill B and Goulson D (2009) Impacts of inbreeding on bumblebee colony fitness under field conditions. BMC Evol Biol 9:e152.

Whiting PW (1943) Multiple alleles in complementary sex determination of Habrobracon. Genetics 28:365-382.

Winkler CJ, Ponce A and Courey AJ (2010) Groucho-mediated repression may result from a histone deacetylase-dependent increase in nucleosome density. PLoS One 5:e10166. 
Woyke J (1963) Drone larvae from fertilized eggs of the honey bee. J Apic Res 2:19-24.

Woyke J (1967) Diploid drone substance - cannibalism substance. Proceedings of the XXI International Beekeeping Congress, Maryland, pp 471-472.

Woyke J (1973) Reproductive organs of haploid and diploid drones of the honeybee. J Apic Res 12:35-51.

Woyke J (1984) Exploitation of comb cells for brood rearing in honey bee colonies with larvae of different survival rates. Apidologie 15:123-136.
Zucchi R, Silva-Matos EV, Nogueira-Ferreira FH and Azevedo GG (1999) On the cell provisioning and oviposition process (POP) of the stingless bees - Nomenclature reappraisal and evolutionary considerations (Hymenoptera, Apidae, Meliponinae). Sociobiology 34:65-86.

Associate Editor: Ricardo Guelerman P. Ramos

License information: This is an open-access article distributed under the terms of the Creative Commons Attribution License, which permits unrestricted use, distribution, and reproduction in any medium, provided the original work is properly cited. 